\title{
Changing medical students' attitudes to learning disability
}

\author{
Ian Hall and Sheila Hollins
}

The Strathcona Theatre Company is made up of professional actors with a learning disability and two directors. As part of the teaching course in the Department of Psychiatry of Disability at St George's Hospital Medical School, the medical students participate in a workshop given by the Company, near the beginning of their attachment in psychiatry. During the two-hour workshop the students are taught a variety of 'ice breaking' games and mimes by members of the Company. This means that early on in the course, students have face to face contact with adults with a learning disability, and furthermore see them in a socially valued role as teachers and leaders. The students usually find the workshop enjoyable, and give posittve feedback although they were unsure how successful the workshop was in changing medical students' attitudes towards people with learning disability. We report an evaluation of students' attitudes before and after the workshop, and show statistically significant changes in attitudes towards people with a learning disability.

\section{The study}

Students were asked to rate how much they agreed with a serles of ten statements concerning people with Down's syndrome, by drawing a line across a $100 \mathrm{~mm}$ line, one end of which represented 'strongly agree', the other 'strongly disagree'. They were asked to do this immediately before and after the workshop. We chose statements concerning Down's syndrome, because this will be familiar to medical students whereas the concept of learning disability may not. Several members of the theatre company have Down's syndrome.

\section{Findings}

Fourteen students participated in the workshop in two successtve firms, making a total of 28 students in the study. The results are presented in Table 1. For each statement, the median percentage agreement and the inter-quartile range are presented for before and after the workshop. Wilcoxon's signed ranks test was used

Table 1. Students' agreement with the statements before and after the workshop

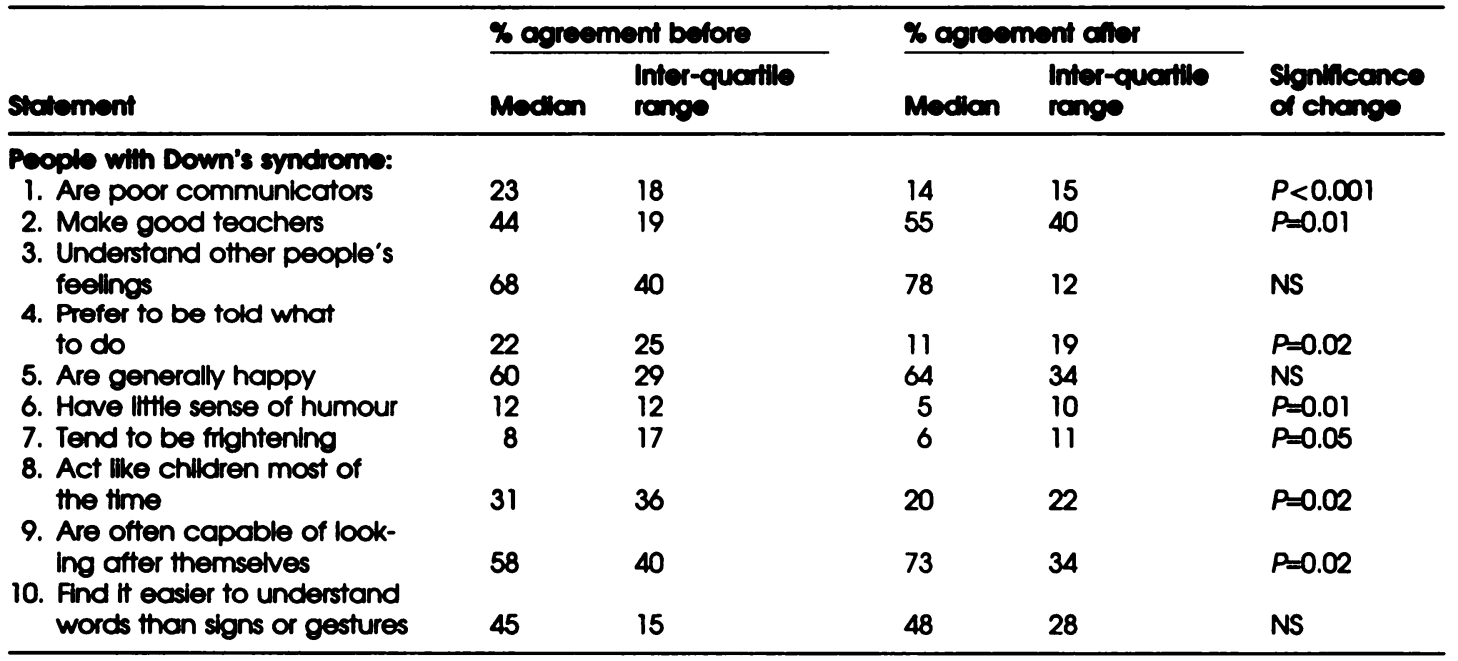

NS=not stgnificant. 


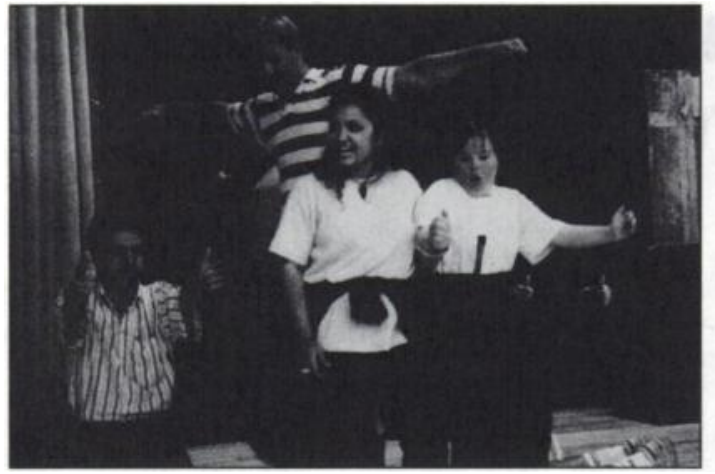

to assess whether the change in scores was of statistical significance. For all statements, there was more agreement with posittve statements and less agreement with negative statements after the workshop than before it. Seven of the changes achieved statistical significance.

\section{Comment}

We have demonstrated that there was a significant shift in medical students' attitude towards people with Down's syndrome after the workshop compared to before it. There was significantly less agreement with the statements that people with Down's syndrome make poor communicators, prefer to be told what to do, have little sense of humour, tend to be frightening, and act like children most of the time. There was significantly more agreement after the workshop with the statements that people with Down's syndrome make good teachers, and are often capable of looking after themselves. We have thus demonstrated the value of the workshop in changing attitudes towards a more enlightened viewpoint.

Communication and disability were both identified in the General Medical Councll (1993) report Tomorrow's Doctors as curricular areas which required more time in a modern medical undergraduate curriculum. Hollins (1988) found considerable agreement about the broad aims of learning disability teaching in United Kingdom medical schools, in particular that these should enable doctors in any speciality, including general practice, to provide sensitive and appropriate care to people with a learning disability. Learning objectives defined by learning disability course organisers typically include more skill and attitude objectives than other parts of the curriculum, recognising that knowledge-based objectives must be supported by a holistic understanding of the social and emotional consequences of chronic disability. Crisp (1994) included the "abilities to communicate professionally with people of all ages, those with learning disabilities (and their familles) . . ." as an important skill, and to have "respect for the views of patients and other carers" as an important attitude to teach undergraduate medical students in psychiatry.

In reviewing learning objectives for the future, curriculum committees will be identifying knowledge, skill and attitude objectives for each subject area. We have demonstrated that by using innovative teaching methods it is possible to change medical students' attitudes to more appropriate ones for helping people with a learning disability. We hope that such methods will ensure that these young doctors will be able to meet the health care needs of people with a learning disability in whatever branch of medicine they choose.

\section{Acknowiedgements}

The authors are grateful to the members and directors of the Strathcona Theatre Company for their contribution to our teaching programme over the last 12 years and for their advice on the questionnaire. We are also grateful to Dr Simon Halstead for statistical advice.

\section{References}

Crisp. A. (1994) Psychiatric contributions to the undergraduate medical curriculum. Psychiatric Bulletin, 18, 257-259.

Graniaral Medical Council (1993) Tomorrow's Doctors: Recommendations on Undergraduate Medical Education. London: General Medical Councti.

Houns, S. (1988) How mental handicap is taught in UK medical schools. Medical Teacher, 10, 289-296.

Ian Hall, Senior Registrar; and Sheila Hollins, Professor, Department of Psychiatry of Disability. St George's Hospital Medical School, University of London, Cranmer Terrace, London SW17 ORE 